\title{
The Effect of the Mind Mapping Strategy on the L2 Vocabulary Learning of Saudi Learners
}

\author{
Nesreen Saud Alahmadi \\ Dept. of Art and Humanities, Taibah University \\ PO Box 3135, Madinah 42351, Saudi Arabia \\ Tel: 014-861-8888Ｅ-mail: Nssahmadi@taibahu.edu.sa
}

Received: December 29, 2019 Accepted: February 6, 2020 Published: February 8, 2020

doi:10.5296/elr.v6i1.16425

URL: https://doi.org/10.5296/elr.v6i1.16425

\begin{abstract}
The aim of this study was to investigate the impact of using the mind mapping strategy on learning vocabulary for Saudi Learners. Fifty female students from the English Language centre at Taibah University in Saudi Arabia were selected to participate in this study. All students were homogenous in terms of their English language proficiency. The students were performing at the intermediate level of the English language. Their level of English language proficiency was determined by the Oxford Placement Test. Participants were divided into two groups: the experimental group and the control group. Twenty-five students in the experimental group were taught vocabulary using the mind mapping strategy for six weeks. The control group was taught using traditional methods of vocabulary teaching, such as memorising. To test the effectiveness of the mind mapping strategy, two types of tests were applied for both groups: a pre-test and a post-test. At the end of the treatment, the results of the post-test showed a significant improvement in Second language (L2) vocabulary acquisition by Saudi learners in the experimental group. The findings of this study indicate some important implications for L2 learning, such as that mind mapping facilitates vocabulary learning by increasing the knowledge and the acquisition of the meanings of the vocabulary words used. It also helped with the vocabulary learning process by increasing the level of the motivation of Saudi students in learning new words.
\end{abstract}

Keywords: Intermediate level, Learning English, Mind mapping, Saudi learners, Vocabulary acquisition

\section{Introduction}

English is one of the most important international languages in the world. It is given significant emphasis in many different areas of studies, such as science, economics, technology and the arts. In the field of education, the English language has been given a high 


\section{$\triangle$ Macrothink}

priority among other languages as it is considered the key to international communication and learning in different educational sectors. In Saudi Arabia, initiatives have been considered to take steps towards improving English language proficiency in the overall academic English language standard not only in schools but also in Saudi universities. Studies have been carried out to test different methods and techniques of learning and teaching English language skills as well as sub-skills, such as grammar and vocabulary. Vocabulary is an important component of English language learning and teaching. Without vocabulary, learners cannot appropriately use any language skill. Learners require sufficient vocabularies to communicate using the target language. It is vital for learners to increase their vocabulary knowledge not only to improve reading and writing skills but also to improve speaking and listening proficiency. Therefore, both learners and teachers should seek different strategies and methods to increase vocabulary comprehension. Moreover, developing a high proficiency and fluency in using a second language (L2) depends on acquiring more productive vocabulary knowledge through developing learners' own personal vocabulary learning strategies (Abdul Aziz \& Yamat, 2016); however, learners and teachers use different methods and techniques to increase vocabulary, such as traditional methods and the rote memorisation of new words, which has proven to be less engaging and sufficient (Wang \& Dostál, 2018) in comparison with the use of strategies that involve using cognitive abilities to improve learning proficiency. Therefore, the aim of this study was to investigate the effectiveness of mind mapping strategies in learning vocabulary for Saudi learners and to test whether mind mapping enhances students' language proficiency by acquiring the meaning of vocabulary and expanding their knowledge of synonyms.

\section{Literature Review}

\subsection{Vocabulary Learning}

Vocabulary is considered a major component of language that language learners must expand to increase L2 proficiency. Because L2 learners require the basic skills to communicate using the target language, effective vocabulary use is central to these skills, which has a positive impact on overall L2 language proficiency. According to Nodoushan and Maibodi (2017, p. 2), to acquire the basic knowledge of vocabulary, learners should recognise the following: 'the spoken form of a word, the written form of a word, the grammatical function of a word, the collocational behaviour of a word, the degree of frequency, the stylistic register constraints of a word, the conceptual meaning of a word, and the association of word with other related words'. In fact, research has shown that L2 acquisition significantly depends on learning vocabulary and that there is a positive connection between language proficiency and vocabulary learning strategies ( $\mathrm{Gu}, 2010)$.

In addition, research on vocabulary learning has shown that learners with a sufficient language proficiency tend to have suitable vocabulary input. Studies have also shown that learners with sufficient language competence have used vocabulary learning strategies (Elashhab, 2019). Moreover, Lia (2005, p. 10) asserts that 'words do not exist as isolated items in a language. That is, words are interwoven in a complex system in which knowledge of various levels of a lexical item is required in order to achieve adequate understanding in listening or reading or produce ideas successfully in speaking and writing'. Thus, language learners must understand a large number of vocabulary words to be able to communicate 
using the target language. According to Schmitt (2010), expanding L2 knowledge of vocabulary words requires not only mastering the meaning of vocabulary words but also understanding their related components in the language, such as the written form, spelling, collocation and grammatical components. Schmitt (2010), associates the term 'vocabulary knowledge' with knowledge of the words and their different properties. In addition, Maskor and Baharudin (2016, p. 261) assert that 'vocabulary knowledge is also known as the depth of vocabulary that brings up to the extent to which the word is understood by speakers. Vocabulary knowledge also means students learn the words with deep meaning, including pronunciation, meaning, spelling, frequency, sound structure, syntax and collocation according to context'. Schmitt (2014) also stated that understanding the different components of vocabulary, such as the lexical forms and phonological components, is vital to mastering L2 proficiency and speaking fluency. Thus, learning vocabulary involves more than knowing the words or their meanings; it involves expanding the knowledge of a word and mastering the different aspects of the process of learning and using vocabulary in various language contexts.

In fact, vocabulary knowledge can indicate a learner's proficiency and can be an indicator of the quality of vocabulary of the learner. According to Pullido and Hambrick (2008), vocabulary is the foundation of language skill proficiency. Learners must acquire and expand the vocabulary of L2 language skills, such as writing, listening, speaking and reading. Thus, vocabulary proficiency effects both the quality and the efficiency of L2 skills. Many studies have been conducted to examine the major role of vocabulary in L2 proficiency (Milton, 2013; Saengpakdeejit, 2014; Barekat \& Karimi, 2012; Crookall \& Oxford, 1990; Hassanzadeh \& Khatib, 2011). Milton (2013) states that the knowledge of vocabulary should be based on both the quantity and the quality of the vocabulary, and second language learners should understand the meaning of vocabulary to communicate accurately using L2. Therefore, a lack of vocabulary knowledge has a negative impact on the efficiency of using the four skills of L2. Consequently, one of the foremost challenging tasks of learning L2 is the acquisition and understanding of vocabulary. Learners should be assisted using all methods to overcome this issue. Thus, it is the task of researchers and practitioners to identify methods to facilitate learning and understanding L2 vocabulary. Innovative methods and strategies for learning and for teaching vocabulary should be identified. Seeking effective strategies and techniques should include L2 learners' perspectives to understand the process of vocabulary acquisition.

\subsection{Mind Mapping Strategy}

The concept of using the mind mapping strategy was created for the first time by the researcher Tony Buzan. According to Wang and Dostál (2018), Buzan began notetaking in the 1960 s as an effective strategy of memorising for learners. Initially, this method was used to assist students with difficulties in their studies. By applying this method, students have changed their way of thinking and have improved their learning achievements. Consequently, Buzan developed the idea of a notetaking strategy into a book of effective learning strategies. After this, the concept of mind mapping was compared to a city learning map to enhance learners' understanding. Wang and Dostál (2018, p. 1) state that 'Tony Buzan claims; The city centre represents the main idea; the main roads leading from the centre represent the key 
thoughts in your thinking process; the secondary roads or branches represent your secondary thoughts, and so on'. Thus, mind mapping leads the learners' thinking process from one stage to another, which impacts learners' achievements.

The mind mapping strategy is defined as the classification of information and ideas according to the relation between information, such as details, and the ideas associated with this information. Mind mapping can be described as including a central topic and different branches related to the same topic (Abdul Baset, 2016). In addition, the structure of mind mapping can prompt the brain to link ideas, which can strengthen memorisation and understanding. Mind mapping can be used as an illustration tool that links the knowledge of one area to several branches. The classification and the division of ideas into central and branching ideas can transfer knowledge and can help learners be more engaged by making rote memorisation attractive and providing organised pictures that facilitate the learning process (Wang \& Dostál, 2018). In fact, this strategy can engage L2 learners in linking the main ideas into more sub-ideas. It can also help associate ideas with branches elicited from the main ideas, where symbols, words and pictures are used to dominate thinking related to an area of knowledge (Abdul Baset, 2016). Therefore, the more ideas linked using the mind mapping strategy, the easier it is for learners to recall the information associated with these ideas.

Due to the practicality of the nature of mind maps, the connection between ideas and the relative information are commonly used not only in educational sectors but also in business and industry fields of study. According to Li et al. (2010), mind mapping is proven to be an effective tool in learning not only for learners but also for teachers, and this strategy has a positive impact on learners' achievements. Mind mapping has been used in a wider context of learning, such as notetaking, critical thinking and decision making (Li et al., 2010). The effectiveness of mind mapping strategies is supported by many studies on L2 (Genç \& Erdoğan, 2010; Al-Qahtani, 2015; Al-Jarf, 2015). In reference to the results of these studies, mind mapping was used as an effective tool to apply in a variety of language skills, such as reading and writing. The visual aids and the association of ideas through mind mapping have greatly facilitated the learning process of L2. Mind mapping also has a significant impact on knowledge construction by increasing the cognitive ability of learners by expanding their awareness of L2.

In Saudi Arabia, many studies have been conducted to examine the effectiveness of mind mapping in L2 learning skills. For example, Bukhari (2016) examined the impact of mind mapping on EFL writing skills, and the results showed that using the hierarchical structure of the mind mapping strategy in pre-task writing facilitates learners' writings skills. Al-Jarf (2011) studied the impact of mind mapping on speaking skills, specifically in pronunciation. The findings indicated that mind mapping helped the learners apply the activities on phonetics accurately as well as enhanced their motivation to learn the correct pronunciation. Moreover, Aljaser (2017) investigated the effectiveness of mind maps in developing Academic Achievements towards Learning English among Primary School Students' Program, and the findings showed that the achievements of school students have increased significantly among the group of students who learnt using mind mapping. Moreover, Younis (2019) also tested the value of using mind mapping in learners' writing, and the results 
showed that mind mapping has a significant impact on learners by expanding their ideas on topics and writing effective concluding sentences. Thus, the aim of the current study was to investigate whether mind mapping expands Saudi learners' knowledge of vocabulary and to examine whether the results are in line with previous research findings.

\section{Theoretical Framework of Mind Maps}

The procedures of using the mind mapping strategy for vocabulary acquisition and the analysis of the data collected in this study were based on two theoretical frameworks related to testing the cognitive ability of Saudi learners in using vocabulary accurately as well as in understanding the meanings of words by applying them correctly on the post-test.

\subsection{Constructivism Theory}

Constructivism refers to researching the process of acquiring information within the cognitive ability of learners. According to Li et al. (2010, p. 2), 'constructivism believes that learning should be student-centred, and it lays emphasis on students' own construction of new knowledge based upon their past and current experience and knowledge'. In fact, constructivism assumes that L2 learners should be involved in an active learning process rather than a passive learning process. Learners should also be encouraged to expand their knowledge of L2 and to be involved in self-centred learning. Thus, for learners to take control over their own learning styles, they must be exposed to a language input in a way that they can challenge some complicity of learning, and they should also take initiative towards learning different skills (Bruner, 1990). Moreover, constructivism aims to make any learning context relevant to the learners' knowledge and awareness. This relevancy encourages L2 learners to expand their knowledge as well as promotes motivation towards learning (Derry, 1996). In addition, according to Novak (1993) as cited in Bukhari (2016, p. 62), 'humans have greater capacity of making meaning and using language to construct meaning, and the thing that really counts is how to empower human beings to optimize their phenomenal capacity to make meaning, including their awareness and confidence in processes that are involved. This capacity for meaning making is referred to as human constructivism'. Thus, exposing learners to different language tasks provides them with the properties that facilitate the mental process and the cognitive ability to understand and to use new information efficiently. Therefore, the study hypothesis is that using a mind mapping strategy would enable learners to expand their vocabulary and to use a variety of meanings in different contexts related to the vocabulary. Mind mapping would also help L2 learners build on their own knowledge by giving them the opportunity to process the information they have using symbols and pictures and by providing multiple meanings to the vocabulary used.

\subsection{The information Processing Theory}

The second theory used as a basis for this theory is the information processing theory. It is widely acknowledged that learners process information through their cognitive ability to use the information stored in their minds. This information is saved in two different types of memory. The first is short-term memory, in which all information and events are stored only for a short period of time, and this information can be used immediately upon recall. The other type of memory is long-term memory, which refers to the information stored in the mind for a long period of time and that might be saved permanently due to its importance and 
correlation with individuals' personal experiences (Li et al., 2010). In second / foreign language acquisition, when L2 learners are exposed to language input in which information is received, the output of this information from learners is still not fully understood regarding how learners process this information and how it is incorporated in their memories, but some studies have shown that memory is more likely to be stored when it is linked to other ideas and concepts related to the learners' personal experiences (Paivio, 1986).

Consequently, the application of the mind mapping strategy examined in this study seems to be powerful and effective in facilitating and sharpening learners' memories regarding vocabulary. Thus, the characteristics of mind mapping work in alignment with the mechanism of the human brain used for storing and processing information. To conclude, for the information to be retained for a long period, it should be deeply processed for any language input. Therefore, mind mapping is a learning strategy that can be used to process information at a deeper level because it can build on knowledge and can process related information in learners' minds. The act of forming this association between words and ideas or concepts enhances and facilities L2 acquisition.

\section{Statement of the Problem}

One of the most challenging aspects of learning English for Saudi learners at the English Language Centre is learning vocabulary. A vast majority of students face difficulties in applying the tasks related to vocabulary. Some weaknesses observed are the ability to remember vocabulary and to use words in the correct context. The lack of vocabulary knowledge influences not only their proficiency in vocabulary tasks but also in other skills, especially productive skills, such as writing and speaking. Students must apply their vocabulary to fulfil the requirements of tests throughout their studies. Therefore, the aim of this study was to identify an effective method to facilitate vocabulary acquisition for Saudi learners. The research goal of this study was to identify appropriate methods to increase learners' vocabulary and to expand their knowledge of word meaning using the mind mapping strategy. Although some research has been conducted on using mind mapping for different English language skills, few have been conducted at the university level. Thus, the aim was to investigate the effectiveness of using the mind mapping strategy among Saudi students at the university level.

Based on the problem stated, the following research questions were formulated:

1) Does the mind mapping strategy improve the level of vocabulary acquisition for Saudi learners?

2) To what extent does using mind mapping increase Saudi learners' English language proficiency?

\section{Methodology}

\subsection{Participants}

Fifty Saudi EFL students took part in this study. All participants were females at the intermediate level who studied English as a core module in the English Language Centre at Taibah University. All students were native speakers of Arabic. English language proficiency was determined using an English language proficiency test (Oxford Placement Test) to ensure the homogeneity of the participants. The participants were divided into two groups. 


\section{Macrothink}

Twenty-five students were in the control group, and 25 were in the experimental group.

\subsection{Instruments}

The instruments employed to collect data were based on three types of tests. The first test was the Oxford Placement Test used to select the correct level of English language proficiency for students. Before beginning the treatment, all students in both groups took the pre-test. At the end of the treatment, a post-test was administered to both groups to compare the results and to examine the effectiveness of using the mind mapping strategy for the acquisition of vocabulary.

\subsection{Procedures}

To conduct the experimental research, 50 Saudi students at Taibah University were selected based on their level of English language proficiency. All students studied English as one of the core modules of the preparatory year. All students received marks between 75 and 80 of 100 on the Oxford Placement Test based on the criteria of dividing the student level. Grades between 70 and 80 are equal to the level (A2), which placed the students at the intermediate level of English language proficiency. The students were then divided equally into two groups. Group (A), which served as the experimental group, consisted of 25 students. Group (b) consisted of 25 students as well and served as the control group. Before beginning the experiment, all students underwent a pre- test to test their vocabulary knowledge. All vocabulary words used in this test were extracted from the course book students needed to complete to pass the academic year. Students in their preparatory year study 'Oxford Q Skills for Success' levels 1, 2 and 3; however, the study was conducted during the first term, and thus the students were only studying at level 1. The Oxford Q Skills for Success course books give the four language skills (Reading, Writing, Listening. And Speaking) the same emphasis, such as for the number of objectives, tasks exercised and online supplementary materials. The book consists of eight units with eight different topics. The topics are; People, Friendship, Education, Food, Fun, Home, Weather and Health. The vocabulary lists for each unit are divided into two lists, and one list is provided at the beginning of the unit. The second list is provided at the end of a unit as illustrated in Figure 1. All the vocabulary lists were selected based on the 'Vocabulary Words from the Oxford 2000 and the Academic Word List'. In fact, the selected vocabulary consisted of different forms in the course book, such as collocation, definition, word categories, synonyms and dictionary use; however, during the first session and at the beginning of the treatment, students had not been provided with any tasks yet except the pre-test to ensure that the students were homogenous in their English language proficiency and vocabulary knowledge level. 


\begin{tabular}{|c|c|c|c|}
\hline \multicolumn{4}{|c|}{ Test on Vocabulary } \\
\hline \multicolumn{2}{|c|}{ UNIT 1-2-3 } & \multicolumn{2}{|c|}{ UNIT 4-5-6 } \\
\hline 1. Fashionable & 15. Vacation & 1. Food & 15. Nature \\
\hline 2. Friendly & 16. Enjoy & 2. Tasty & 16. Sightseeing \\
\hline 3. Heavy & 17. Important & 3. Delicious & 17. Trip \\
\hline 4. Intelligence & 18. Interesting & 4. Cooking & 18. Walk \\
\hline 5. funny & 19. Relaxing & 5. Fruit & 19. Joke \\
\hline 6. kind & 20. Academic & 6. Vegetables & 20. plans \\
\hline 7. Helpful & 21. Boring & 7. Ingredients & 21. Snack \\
\hline 8. opposite & 22. Busy & 8. Seafood & 22. Coffee \\
\hline 9. Think & 23. Difficult & 9. Meat & 23. Support \\
\hline 10. Patient & 24. Quite & 10. Meal & 24. Expensive \\
\hline 11. People & 25. Attend & 11. Fresh & 25. Handmade \\
\hline 12. Advice & 26. Uniform & 12. popular & 26. Invite \\
\hline 13. Smart & 27. Break & 13. Special & 27. Program \\
\hline 14. Fight & 28. Holidays & 14. Event & 28. Favorite \\
\hline
\end{tabular}

Figure 1. Illustrates the list of vocabulary included in the study

In the next stage of the study, vocabulary items from the course book were selected. The plan was based on dividing the treatment over six weeks with one unit from the book per week. Each week, students were taught vocabulary over two sessions. The experimental group was taught vocabulary using mind mapping, and the control group was taught vocabulary using traditional methods, such as providing definitions, matching meanings and providing synonyms. The same vocabulary list was given to both groups. Each list consisted of 16 items based on the content of the book.

The procedures used to present new vocabulary, only for the experimental group, were as follows. First, students were asked to read the vocabulary list to check their comprehension and understanding of the meaning of the vocabulary words. Then, the teacher explained the meaning of each vocabulary word. The students were given instructions regarding how to draw a mind map for each vocabulary word. The vocabulary was written in the centre of the board in the classroom. Students were then asked to add one synonym related to the word. Students were also asked to come up with any words related to the vocabulary word selected based on previous knowledge. All the new vocabulary words were used to build up to the main vocabulary word using the diagram created by the teachers. Students were asked to draw their own mind map for the selected vocabulary word. The same steps were applied during each session for all vocabulary words. Students were asked to take their own notes on the new vocabulary and to keep them for their own use at the end of each session.

It is worth mentioning that these steps were repeated for each set of vocabulary words during each session. Each session lasted about forty to forty-five minutes. Some students were more motivated and showed great interest in drawing their own mind maps and discussing the outcome of the exercise with their classmates before beginning the exercises in the books. Most of the exercises in the book were used as post-activities of mind mapping. These activities included matching each vocabulary word with the correct meaning and underlining 
the correct meaning of each item. The aim of using the post-activities during each session was to ensure students' understanding of the meaning of the vocabulary words introduced.

\subsection{Results}

The aim was to investigate the effectiveness of mind mapping strategy in learning vocabulary for Saudi learners. A placement test and post-test were developed and employed to assess the language proficiency of the participants. The results were first analysed, then compared between the two groups using A test statistics from the sample which is used to obtain the ratio of t-test values. Based on the results, a comparison between the experimental and control groups was made.

\section{A-Placement Test Results of the Control and Experimental Groups}

$\mathrm{H}_{0}: \mu_{\mathrm{control}}=\mu_{\text {experiment }}$

$\mathrm{H}_{1}: \mu_{\text {control }} \neq \mu_{\text {experiment }}$

$\alpha=0.050$

Table 1. Descriptive statistics of the placement test of the control \& experimental groups

\begin{tabular}{llccccccc}
\hline & Group & $\mathrm{N}$ & $\mu$ & $\delta$ & SEM & $\mathrm{T}$ & DF & $\mathrm{P}$ \\
\hline \multirow{2}{*}{ Placement } & Control & 25 & 75.48 & 4.03107926 & 4.114203041 & 1.711 & 24 & 0.050 \\
& Experimental & 25 & 75.4 & 3.41760149 & 3.488074923 & & 24 & 0.050 \\
\hline
\end{tabular}

As shown in Table 1, the results indicate that students in the experimental group are in average scores of Intermediate English Language level and have the same vocabulary and language proficiency as students in the control group. The results indicate that the experimental group came out with an average of (75) as the $\mathrm{T}$ test value is $(\mathrm{t}<\mathrm{T})$, we accept $\mathrm{H}_{0}$, to ensure the homogeneity of the participants in this study. Thus, the means have the same average scores among both groups with T Value of (4.03) and (3.41) respectively.

However, Table 2 shows the results of the t-test, which clearly shows the difference in language proficiency and vocabulary acquisition among participants in the control and experimental groups.

\section{B-Post-Test Results of Control and Experimental Groups}

$\mathrm{H}_{0}: \mu_{\mathrm{control}}=\mu_{\text {experiment }}$

$\mathrm{H}_{1}: \mu_{\text {control }} \neq \mu_{\text {experiment }}$

Table 2. Descriptive statistics of the post-test of the control \& experimental groups

\begin{tabular}{lllllllll}
\hline & Group & $\mathrm{N}$ & $\mu$ & $\Delta$ & $\mathrm{SEM}$ & $\mathrm{T}$ & $\mathrm{DF}$ & $\mathrm{P}$ \\
\hline \multirow{2}{*}{ Post test } & Control & 25 & 82.16 & 7.43871 & 7.592101 & 1.711 & 24 & 0.050 \\
& Experimental & 25 & 89.48 & 5.727966 & 5.846081 & & 24 & 0.050 \\
\hline
\end{tabular}


As shown in Table 2, students in the experimental group performed better compared to students in the control group. The average score' results of the control group was (82.1), and (89.4) in the experimental group. Thus, the $\mathrm{t}$ - test value is $(\mathrm{t}=-4.63044)$, indicating that $\mathrm{t}>\mathrm{T}$; hence, we reject $\mathrm{H}_{0}$. That means that students in the experimental group show, on average, significant improvement in L2 vocabulary acquisition compared to students in the control group during the post-test. Further, results of both tests (the placement and the post-test) are shown for each group.

\section{C-Results of the Placement and Post-Test for the Control Group}

$\mathrm{H}_{0}: \mu_{\text {placement }}=\mu_{\text {post }}$

$\mathrm{H}_{1}: \mu_{\text {placementl }} \neq \mu_{\text {post }}$

Table 3. Descriptive statistics of the placement and post-test for the control group

\begin{tabular}{lllllllll}
\hline & Test & $\mathrm{N}$ & $\mu$ & $\delta$ & $\mathrm{SEM}$ & $\mathrm{T}$ & $\mathrm{DF}$ & $\mathrm{P}$ \\
\hline Control & Placement & 25 & 75.48 & 4.031079 & 4.114203 & 1.711 & 24 & 0.050 \\
& Post & 25 & 82.16 & 7.43871 & 7.592101 & & 24 & 0.050 \\
\hline
\end{tabular}

Table 3 shows results of the control group during both the placement test and the post-test. The average number of placement tests for this particular group was (75) in the beginning of the course and (82) at the end of six weeks. It is worth mentioning that the group has a t-test value of $(\mathrm{t}=-4.411956914)$, and with $\mathrm{t}>\mathrm{T}$, we reject $\mathrm{H}_{0}$, meaning that students in the control group show greater improvement in L2 vocabulary acquisition during the post-test compared to during the placement test when taught by traditional methods. However, more significant results were found in the experimental group, who were taught using mind mapping strategy. The results are illustrated in Table 4.

$$
\begin{aligned}
& \text { D- Results of the Placement and Post-Test for the Experimental Group } \\
& \mathrm{H}_{0}: \mu_{\mathrm{placement}}=\mu_{\mathrm{post}} \\
& \mathrm{H}_{1}: \mu_{\mathrm{placement}} \neq \mu_{\mathrm{post}}
\end{aligned}
$$

Table 4. Descriptive statistics of the placement and post-test for the control group

\begin{tabular}{lllllllll}
\hline & Test & $\mathrm{N}$ & $\mu$ & $\delta$ & $\mathrm{SEM}$ & $\mathrm{T}$ & $\mathrm{DF}$ & $\mathrm{P}$ \\
\hline \multirow{2}{*}{ Experimental } & Placement & 25 & 75.4 & 3.417601 & 3.488075 & 2.492 & 24 & 0.010 \\
& Post & 25 & 89.48 & 5.727966 & 5.846081 & & 24 & 0.010 \\
\hline
\end{tabular}

As shown in Table 4, with a t-test value of 12.27, $\mathrm{t}>\mathrm{T}$, and we reject $\mathrm{H}_{0}$ with a confidence interval of 0.010 . Students in this group have an average of (75) in the placement test before the treatment and an average of (89) in the post-test after the treatment. This indicates that 
these students on average show significant improvement in L2 vocabulary acquisition during the post-test compared to their language capability during the placement test.

\section{Discussion}

Although many studies have examined the effectiveness of mind mapping in learning in general and pertaining to the English language in particular, this study attempted to test the extent to which mind mapping can help in learning L2 vocabulary in the Saudi Arabian context. Based on the hypotheses and objectives, a t-test was employed to measure and compare the results and assess language proficiency before and after the treatment.

The t-test analysis shows that students in the experimental group with marks distribution of (75.48 \pm 4.03107926$)$ and students in the control group with a distribution of $(75.4 \pm$ 3.41760149) have the same language proficiency in general and vocabulary competence in particular. This ensured homogeneity in their language proficiency before the treatment.

However, students in both groups were able to improve their capability during the post-test, with a confidence interval of $\alpha=0.10$. They studied the same vocabulary for six weeks but by using different methods.

The t-test analysis on the post-test results shows that students in the experimental group improved their capability considerably during the treatment, compared to students in the control group, with a confidence interval of $(\alpha=0.10)$. These findings are validated by previous research (Bukhari 2016), which concluded that mind mapping, if used effectively, can enhance learning, particularly writing skills. In addition, the findings indicate that students experienced a significant improvement in vocabulary during the six-week treatment. In particular, students in the experimental group showed significant improvement when they were taught the same vocabulary but using mind mapping strategy. Moreover, students in this group showed great interest in learning vocabulary by building their own maps during lessons. Furthermore, mind mapping, through drawing and planning maps, also increased students' motivation, which reflected positively in their overall performance at the end of the treatment. In fact, increased motivation is another important factor that distinguishes this study from existing literature. Liu (2014), cited in Nodoushan and Maibodi (2017), asserted that that using mind mapping could be time-consuming for teachers. Muhib et al. (2014), who investigated the impact of mind mapping on English language learning, claimed that mind mapping is not easy to apply during English lessons, and hence, it can be time-consuming, making it challenging for both learners and teachers. Mind mapping also demands substantial organization skills. However, this strategy has received positive feedback from students in this study. It has expanded their vocabulary irrespective of the time spent on drawing maps.

In addition, the significant difference in the results of both groups and between the placement test and the post-test indicates that mind mapping in vocabulary learning is a valuable tool. Learners build knowledge by linking words and categorising them, thus developing a comprehensive understanding of the words and expanding their knowledge. In fact, mind mapping can help students to organise their ideas, maintain attention during class and classify and categorise words appropriately. The results also show that mind mapping can be used as an effective tool to generate ideas and link words to one concept or theme. It also, assists the learners in this study to organise their ideas and facilities their note taking skills when they 
tried to bring the words together.

Thus, mind mapping has greatly benefited participants in this study and improved their English language proficiency by expanding their knowledge, building their vocabulary, motivating them to learn and assisting them in developing their own learning strategies by composing different mind maps that match their interests.

\section{Conclusion}

This study aimed to test the impact of mind mapping strategy on learning vocabulary for Saudi Arabian learners. The results showed a significant difference between vocabulary acquisition of the experimental group and that of the controlled group. Mind maps played an important role in vocabulary learning in this particular context. Also, different aspects of vocabulary can be used, such as classification of words, categorisation and synonyms.

Participants were able to expand their vocabulary and create their own vocabulary by learning more related words. Mind maps primarily assisted students in generating connections within their vocabulary. Thus, connecting learners' existing knowledge of words to the new vocabulary in their course books has helped learners to better understand vocabulary. Consequently, when learners processed the information and tried to link the vocabulary with other items, their knowledge of the meaning improved significantly. In addition, mind map strategy facilitated knowledge acquisition by helping Saudi Arabian learners to overcome the difficulties in memorising vocabulary; it provided them with a technique to recall and use words effectively. Students were also motivated to draw their own mind maps, which helped the learning process remarkably.

Therefore, the mind mapping strategy could help both learners and teachers to build knowledge, enhance communication using L2 and create innovative methods to understand and expand vocabulary comprehension.

\section{Pedagogical Implication and Limitation}

This study shows that mind mapping is an effective strategy for L2 learning. It can help enhance learners' awareness of different L2 structures. Mind mapping could improve learning outcomes such as the ability to use vocabulary in different contexts. Also, it can solve certain issues faced by learners, such as the lack of focus when information is process in L2 learning, learning could have better opportunity to develop the knowledge they already have and overcome their learning obstacles. Also, given that this study revealed the extent to which mind mapping motivated learners, it can be used as an effective learning tool in L2 acquisition that improves the learning process and language proficiency. Nevertheless, the application of mind mapping is not limited to learning vocabulary skills, it can also be applied to various other L2 skills such as writing and speaking.

This study has certain limitations. Mind mapping strategy was only tested in vocabulary learning. It may reveal different results if tested on skills such as speaking, reading and writing. Moreover, second language acquisition is influenced by different internal and external factors, such as gender and age. This study included female L2 learners at the university level, and thus, we may have different results if the study participants were from a different age group and gender. 


\section{Macrothink}

\section{References}

Abdul Aziz, A., \& Yamat, H. (2016). The use of the mind mapping technique in increasing students' vocabulary list. Journal of Education and Social Sciences, 4, 105-113.

Abdul Baset, H. (2016). Digital mind maps: Their activities in education and learning. E-Learning Journal, 12, 89- 98.

Al-Jarf, R. (2011). Teaching spelling skills with a mind-mapping software. Asian EFL Journal Professional Teaching Articles, 53, 4-16.

Al-jarf, R. (2015). A model for enhancing EFL freshman students' vocabulary with mind mapping software. The Journal of Teaching English for Specific and Academic Purposes, 3(3), 67- 77.

Aljaser, A. M. (2017). The effectiveness of electronic mind maps in developing academic achievement and the attitude towards learning English among primary school students. International Education Studies, 10(12), 80. https://doi.org/10.5539/ies.v10n12p80

Al-Qahtani, M. (2015). The importance of vocabulary in language learning and how to be taught. International Journal of Teaching and Education, 3(3), 22, 23-26. https://doi.org/10.20472/TE.2015.3.3.002

Barekat, B., \& Karimi, S. (2012). Vocabulary learning strategies: The effect of level of proficiency on the strategy use. Science Road Publishing Corporation Journal, 6(1), 79-87.

Bukhari, S. (2016). Mind mapping techniques to enhance EFL writing skills. International Journal of Linguistics and Communication, 1(4), 58-77. https://doi.org/10.15640/ijlc.v4n1a7

Bruner, J. (1990). Acts of meaning. Cambridge, MA: Harvard University Press.

Buzan, T., \& Buzan, B. (1993). The Mind Mapbook: How to Use Radiant Thinking to Maximize Your Brain's Untapped Potential. New York.

Crookall, D., \& Oxford, R. (1990). Vocabulary learning: A critical analysis of techniques. TESL Canada Journal, 7(2), 9-30. https://doi.org/10.18806/tesl.v7i2.566

Derry, S. J. (1996). Cognitive schema theory in the constructivist debate. Educational Psychologist, 31(3/4), 163-174. https://doi.org/10.1080/00461520.1996.9653264

Elashhab, S. (2019). Exploring vocabulary learning strategies of Saudi female university students: Perspectives and use. International Journal of Language and Linguistics, 6(3), 47-53. https://doi.org/10.30845/ijll.v6n3p7

Genç, B., \& Erdoğan, B. (2010). English as a world language in academic writing. The Reading Matrix, 10(2), 142-151.

Gu, Y. (2010). Learning Strategies for Vocabulary Development. Reflections on English Language Teaching, 9(2), 105-118.

Hassanzadeh, M., \& Khatib, M. (2011). Vocabulary learning strategies of Iranian 
upper-intermediate EFL learners. Journal of International Education Studies, 4(2), 144-152. https://doi.org/10.5539/ies.v4n2p144

Lai, Y. L. (2005). Teaching vocabulary learning strategies: Awareness, beliefs, and practices. A survey of Taiwanese EFL senior high school teachers (Unpublished doctoral dissertation). University of Essex, England.

Li, M., Yang, Y., \& Chen, H. (2010). Using mind maps as a strategy for vocabulary acquisition in Chinese universities. Proceedings from; Computational Intelligence and Software Engineering (CiSE), International Conference on (pp. 1-3). https://doi.org/10.1109/CISE.2010.5677128

Liu, Y., Zhao, G., \& Bo, Y. (2014). The effect of mind mapping on teaching and learning: a meta-analysis. Standard Journal of Education and Essay, 2(1), 17-3.

Maskor, S. M., \& Harun, B. (2016). Receptive Vocabulary Knowledge or Productive Vocabulary Knowledge in Writing Skill, Which One Important? International Journal of Academic Research in Business and Social Sciences 6(11), 1-11. https://doi.org/10.6007/IJARBSS/v6-i11/2395

Milton, J. (2013). Measuring the contribution of vocabulary knowledge to proficiency in the four skills. In C. Bardel, C. Lindqvist, \& B, Laufer (Eds.), L2 Vocabulary acquisition, knowledge and use: New perspectives on assessment and corpus analysis, European Second Language Association, 1(2), 57-78.

Muhib, A., Anggani L, D., \& Hartono, R. (2014). Mind mapping and everybody writes techniques for students with high and low writing achievement. English Education Journal, 4, 99-105.

Nodoushan, T., \& Maibodi, A. (2017). The impact of the mind mapping strategy on vocabulary use in the writing of Iranian EFL learners. The 2nd International Conference on New Trends in English Language, Ardabil, Iran.

Novak, J. D. (1993). Human constructivism: A unification of psychological and epistemological phenomena in meaning making. International Journal of Personal Construct Psychology, 6, 167-193. https://doi.org/10.1080/08936039308404338

Paivio, A. (1986). Mental representations. New York: Oxford University Press.

Pulido, D., \& Hambrick, D. Z. (2008). The virtuous circle: Modeling individual differences in L2 reading and vocabulary development. Reading in a Foreign Language, 20(2), 164-190.

Saengpakdeejit, R. (2014). Awareness of vocabulary learning strategies among EFL students in Khon Kaen University. Theory and Practice in Language Studies, 4(6), 1101-1108. https://doi.org/10.4304/tpls.4.6.1101-1108

Schmitt, N. (2010). Researching vocabulary: A vocabulary research manual. New York: PalgraveMacmillan. https://doi.org/10.1057/9780230293977

Schmitt, N. (2014). Size and depth of vocabulary knowledge: What the research shows. 


\section{Macrothink}

Education and Linguistics Research

ISSN 2377-1356 2020, Vol. 6, No. 1

Language Learning, 64, 913-951. https://doi.org/10.1111/lang.12077

Wang, X., \& Dostál, J. (2018). Using a mind map to learn English vocabulary. 2nd International Conference on Education and E-Learning, At Bali, Indonesia. https://doi.org/10.1145/3291078.3291121

Younis, M. (2019). Luminosity of mind mapping in teaching writing. Teacher Education and Curriculum Studies, 4(1), 1-8. https://doi.org/10.11648/j.tecs.20190401.11

\section{Copyright Disclaimer}

Copyright reserved by the author(s).

This article is an open-access article distributed under the terms and conditions of the Creative Commons Attribution license (http://creativecommons.org/licenses/by/3.0/). 